\title{
DISCIPLINA CORPORAL E A VIRTUDE DA CARIDADE: A CONDIÇÃO DAS VIÚVAS SEGUNDO AMBRÓSIO DE MILÃO
}

\section{CORPORAL DISCIPLINE AND THE CHARITY'S VIRTUE: THE CONDITION OF WIDOWS ACCORDING TO AMBROSE OF MILAN}

Larissa Rodrigues Sathler Dias ${ }^{1}$

Resumo: Neste artigo, nos propusemos a analisar o discurso proferido pelo bispo Ambrósio de Milão, em sua obra intitulada "Sobre as Viúvas", com intuito de contextualizar socialmente esse gênero de vida próprio das comunidades cristãs do século IV. Para tal, compreende-se que tanto o ascetismo como a prática caritativa recebeu, nessa literatura, um contorno peculiar, pois são tidos como atividades essenciais para a construção da representação das viúvas cristãs na Antiguidade Tardia, ao mesmo tempo em que oportunizou uma autêntica ascensão feminina na hierarquia da Igreja. Nesse sentido, nosso objetivo foi analisar uma série de normas comportamentais, principalmente as que dizem respeito à abstinência sexual e a execução das boas obras, que permitiram ao episcopado moldar a conduta das viúvas. Aqui a construção desse corpo disciplinado para a santificação é constituída sob um paradoxo, uma vez que, ao ser colocado em evidência, expõe a diferença de gênero no Baixo Império Romano.

\footnotetext{
${ }^{1}$ Graduanda em História pela Universidade Federal do Espírito Santo (UFES). Membro do Laboratório de Estudos sobre o Império Romano (LEIR), além de fazer parte do Programa Institucional de Iniciação Científica, atuando como voluntário do Conselho Nacional de Desenvolvimento Científico e Tecnológico (CNPq), com o subprojeto intitulado: "Disciplina corporal e formação das mulheres cristãs: a condição das virgens e viúvas segundo Ambrósio de Milão", sob orientação do prof. Dr. Gilvan Ventura da Silva. Tem como foco de estudo História Antiga e Medieval, com ênfase em Império Romano e Antiguidade Tardia.
} 
Palavras-chave: Antiguidade Tardia; Ambrósio; Cristianismo; Disciplinarização; Gênero; Viúvas.

\begin{abstract}
In this article, we analise bishop's Ambrose of Milan work "On Widows", seeking to socially contextualize this life style typical of the fourth century christian communities. For such end, it is understood that both asceticism and charitable practices received, in this bibliography, a peculiar form, regarded as activities that are essential to the construction of the representation of the christian widows in Late Antiquity, while also allowing an authentic female ascension in the Church hierarchy. In that sense, our goal was to analyse a series of behaviour standards, especially those regarding sexual abstinence and the execution of good deeds, which allowed the episcopacy to shape the widow's manners. Here the construction of this body that is disciplined seeking sanctification is built upon a paradox, once that, when brought forward, exposes the gender differences in the Lower Roman Empire.
\end{abstract}

Keywords: Late Antiquity; Ambrose; Christianity; Disciplinarization; Gender; Widows.

As inúmeras transformações que atingiram o Império Romano Tardio culminaram no fortalecimento do credo cristão ao mesmo tempo em que permitiram uma maior participação pública da figura feminina em meio a uma sociedade patriarcal. Como destacou Ramón Teja (1999, p. 216), “[...] as mulheres alcançaram nessa época destaque na vida política, social e religiosa de forma que não se havia conhecido em momento algum do Mundo Antigo". Para compreendermos melhor essa mudança social que atingiu Roma com ritmo próprio é preciso recuperar as práticas vigentes no período que antecedeu a fase final do Império. No entanto, deve-se ter em mente que nem todas as estruturas sociais foram alteradas. Como afirma Peter Brown (1989, p. 215), "quer se trate da vida dos notáveis numa cidade antonina ou dos costumes de um cristão 
do Império Romano Tardio, [...] encontramos a necessidade ancestral de uma comunidade pública em que a existência do indivíduo privado é totalmente impregnada pelos valores da comunidade”. Sendo assim, ressaltamos que apesar das diversas mudanças em relação à representação do corpo feminino, mais propriamente do corpo da viúva aqui trabalhado, estas são expressões de uma dominação masculina existente desde o Principado e que agora repercute na sociedade romana sob uma nova roupagem.

Segundo John Scheid (1990, p. 465-467), a vida religiosa dos romanos se desenrolou em vários planos, dependendo de cada comunidade. Todavia a posição da mulher nunca esteve em primeiro plano. Impedidas de exercer um ofício religioso público no paganismo, as mulheres, muitas vezes, eram proibidas de participar dos ritos sacrificiais sangrentos ou pelo menos de seu momento mais importante. Até mesmo as vestais, tidas como exceções na hierarquia sacerdotal romana, estavam submetidas ao poder do sumo pontífice e do colégio pontifical. Outro caso particular de sacerdócio feminino são as flamínicas. Como esposas de sacerdotes romanos, tais mulheres fugiam à regra, obtendo um papel de destaque nos ritos. Porém, sua função de destaque só vigorava devido ao laço de união com o marido, ou seja, apenas pela presença da figura masculina. Scheid (1990, p.488-493) conclui o seguinte a respeito da ascensão religiosa feminina:

[...] e quando detinham responsabilidades religiosas, exerciamnas de noite, à porta fechada, ou em santuários suburbanos, ou mesmo nos limites do território, por vezes por privilégio especial [...]. Esta marginalização religiosa era justificada pela opinião 
pública de que a mulher era incapaz de uma prática racional e razoável da religião, de qualquer religião.

Longe de adentrar as questões que envolvem o corpo feminino nos ritos pagãos, essas considerações iniciais têm por propósito nos levar a refletir como a sociedade de fins da República e início de Império percebia a ligação da mulher com a religião. Manifestando-se como um elemento cultural, as cerimônias realizadas pela antiga religio nos permitem analisar a posição do cristianismo dentro da antiga ordem social. Por outro lado, evidenciam a ideia de que mesmo com uma restrita participação feminina na hierarquia eclesiástica, os valores patriarcais da sociedade romana foram mantidos pelos cristãos.

Constantino governou, como cristão declarado, um império que diferia não apenas economicamente, como também socialmente da época clássica. A respeito de Constantino, Teja (1999, p.43) destaca que: “[...] quando se fez seguidor da nova religião, os cristãos não eram obrigados a continuar aceitando algumas idéias que estavam profundamente arraigadas nos estratos da população [...]”. Sob o governo desse imperador, a Igreja ascendeu graças ao patrocínio imperial. ${ }^{2}$ Nesse momento, magníficas basílicas foram construídas, o clero foi cumulado de benefícios e o bispo obteve acesso direto aos governadores de província. Além disso, os celibatários ganharam destaque como patronos dos pobres e protetores das mulheres influentes através da direção de grupos espiritu-

\footnotetext{
2 "O termo "Igreja" provém do grego Ekklesia, e significa conjunto de cidadãos de uma polis. O termo foi adaptado para o cristianismo e passou a expressar a reunião dos primeiros cristãos para a celebração do culto" (SILVA; SOARES, 2012, p.142). Todas as datas indicadas no artigo est
} 
ais de viúvas e virgens, o que lhes conferiu grande importância no século IV. A ascensão do credo cristão associada à construção de um suporte ideológico que visava a definir as competências dos sacerdotes conferiu aos bispos poder político e influência social dentro das congregações. ${ }^{3}$ Como exemplo deste cenário, podemos destacar a suposta influência exercida por Ambrósio, bispo da sé de Milão, nas decisões tomadas por imperadores como Graciano, Valentiniano II e Teodósio I. Ao analisar as relações de poder entre o Estado romano e a Igreja, ${ }^{4}$ Márcia Lemos (2013, p.47) destaca pontos importantes acerca do arranjo estabelecido por Ambrósio e a casa imperial:

[...] Graciano, instruído na fé nicena pelo clérigo, adotou uma série de medidas em benefício da Igreja: convocou o concílio de Aquiléia (381), com o objetivo de eliminar o arianismo no Império Romano do Ocidente; reuniu o concílio de Roma (382) para tratar dos pricilianistas [...]; ordenou a remoção do altar da Vitória na sala do Senado (382), aboliu as subvenções e as imunida-

3 Ramón Teja (1999, p.75) relaciona a influência do bispo na sociedade do Império Romano Tardio a fatores múltiplos. Sem dúvida é consequência da política religiosa dos imperadores cristãos, porém, "essa influência seria imaginável se nesta época não houvessem ascendido ao episcopado uma larga série de personagens que por seu status social, sua riqueza familiar, sua formação cultural estavam chamados a dirigir a sociedade de seu tempo".

${ }^{4}$ Lemos (2014) trabalha em seu artigo, As relações de poder entre o Estado Romano e a Igreja: uma história de conflito e conciliação, a ideia de Estado Romano como uma instituição administrativa que se transforma mediante a um esforço de reorganização da Orbis Romani a partir de Galieno, desenvolvida por Aureliano e Probo e estabelecida sob os reinados de Diocleciano e Constantino. Aqui, diversas mudanças de caráter político-administrativo permitiram que o Estado Romano assumisse novas feições em meados do século III, de modo que não podemos falar mais de um sistema ideológico nos moldes do Principado e sim do Dominato. 
des concedidas aos sacerdotes pagãos e vestais, instituiu leis antipagãs.

Quanto à influência sob Valentiniano II, ao responder contrariamente o pedido de Símaco de restaurar os direitos e prerrogativas dos cultos pagãos, o clérigo "empenhou-se em demonstrar que a Igreja não poderia ficar submetida à autoridade civil" e "exigiu que o imperador respeitasse a autonomia da Igreja para deliberar sobre os temas relacionados à fé” (LEMOS, 2013, p. 47). E por fim, sob Teodósio, defensor do credo niceno, atuou vigorosamente contra os arianos e os pagãos. ${ }^{5}$ Aqui, não só a autonomia eclesiástica foi reafirmada, como também o próprio direito da Igreja de interferir nas designações religiosas. Não obstante, o bispo de Milão assegurou, dentro de uma tradição paulina, o pagamento de tributos e a obediência ao César, mas respaldando sempre que o imperador está dentro da Igreja e não acima dela. Ou seja, o governante, como membro da Igreja, deveria submeter-se à hierarquia eclesiástica (quando o assunto era a fé) e a Cristo, único mediador entre Deus e os homens. ${ }^{6}$

Decerto, as práticas cotidianas de Ambrósio expressaram, em grande medida, o perfil variado dos membros pertencentes à congregação milanesa. Sendo assim, sua atuação não ficou restrita apenas ao

\footnotetext{
${ }^{5}$ Lemos (2013, p. 47) destaca que, nesse momento o bispo ariano patriarca de Constantinopla, Demófilo, foi substituído por um niceno, como também, em 385, fora renovada a proibição dos sacrifícios pagãos. Em 391 qualquer cerimônia pagã estava proibida.

${ }^{6}$ Para melhor compreensão deste pensamento ambrosiano ver: Walter Ullmann, Historia Del pensamento político en Edad Media. Barcelona: Ariel, 1983.p. 40-41.
} 
envolvimento com as controvérsias político-religiosas, como também esteve ligada a uma vasta produção de textos literários que visavam a afirmar a identidade cristã por meio do combate ao pecado. Quanto a isso, percebemos que em todo o Império, mediante a solidificação do episcopado, inovaram-se os discursos literários que tratavam de disciplinar, principalmente, a figura feminina, como afirma Silvia Siqueira (2003, p. 376-7),

\begin{abstract}
A literatura cristã primitiva e a patrística apresentam teorias e regras direcionadas para as mulheres com enfoques discursivos masculinos de clérigos e monges. Trazem [...] regras extremamente rigorosas em relação aos comportamentos sociais e religiosos dos cristãos [...] trata-se de discursos que [...] estabelecem um padrão comportamental.
\end{abstract}

Nos séculos IV e V vemos ainda, nos meios cristãos, a emergência de inúmeros debates acerca da mulher, das práticas ascéticas e caritativas, como também do matrimônio. Aqui, o modelo de corpo feminino ideal ganhou destaque devido à ascensão da figura de Maria. Prova disso é que, no chamado Concílio de Éfeso (431), a Igreja fez de Maria o modelo de aplicações das teorias episcopais sobre a mulher (TEJA, 1999).

Em conformidade com uma nova representação feminina, o tratado escrito por Ambrósio de Milão, em 377, direcionado às viúvas, o De uiduis, nos permite caracterizar e definir a ordem das viúvas cristãs e sua importância nas comunidades cristãs. Formulando normas que enaltecem a virgindade e a viuvez diante da tradicional opção do matrimônio, Ambrósio propõe uma situação na qual estas mulheres alcançam 
um patamar de vida elevado. Nesse sentido, a viuvez representaria uma libertação da condição feminina, uma vez que viver submetido ao marido seria uma forma de servidão: "Assim, pois, se tem provado que o matrimônio é uma atadura por meio da qual a mulher está ligada [...]" (De uiduis. 69); “Se, pois, um bom casamento é a servidão, que será um mal?" (De uiduis. 69); “Assim, pois, a casada, e não a viúva é condenada aos trabalhos e aos sofrimentos da geração dos filhos" (De uiduis. 81).

Baseado na primeira carta de Paulo (I Co 7, 39-40) aos coríntios, que diz que, "a mulher está ligada enquanto vive ao marido; contudo, se falecer o marido, fica livre para casar com quem quiser [...]", Ambrósio converte a viuvez em um prêmio, pois a viúva tenderia a governar a si mesma. Liberta e seguindo a disciplina da Igreja, a viúva poderia recolher os frutos de uma conduta virtuosa: "Oh viúvas, tenham aprendido que [...] não necessitas da ajuda da natureza e que podeis manter um propósito saudável, e que não necessitais de proteção doméstica, pois podes alcançar o vértice do poder público" (De uiduis, 9.52).

O reconhecimento público numa sociedade dominada pelo elemento masculino era, sem dúvida, uma das recompensas mais estimulantes para a devoção total manifesta pelas viúvas. Bem situadas na sociedade, as viúvas que recebiam o ensinamento cristão abriram seu caminho em um ambiente tradicional. Após a morte do esposo, a viúva alcançava certa independência econômica e, na condição de administradora de si mesma e dos seus próprios bens, uma ampla liberdade de movimentos e um papel de primeira ordem no exercício da caridade. 
Ao seguirem os preceitos da hospitalidade e da humildade, as viúvas manteriam um compromisso religioso que as aproximariam da elite sacerdotal. Autores como Brown (1989), Rosário Sáez (1991), Mercedes Serrato (1999), Bruno Zétola (2004) e Monique Alexandre (1990) defendem a ideia de que as viúvas tornaram-se patronas de clérigos e monges por meio de suas doações e da construção de Igrejas, mosteiros e hospitais. Segundo Alexandre (1990, p. 551), “O poder das mulheres é também o das doadoras, das fundadoras. Na passagem do evergetismo antigo à caridade cristã, voltada para a Igreja, os pobres [...] e os mosteiros, elas detêm a partir do século IV, o seu papel”. Impedidas de assumir posições de poder na Igreja, do mesmo modo que na administração imperial, as viúvas da aristocracia se notabilizaram pelas obras de caridade que executaram. Nesse caso, a própria caridade é tida como um preceito disciplinar. Ser piedoso e contribuir para a edificação do Reino dos Céus constituiriam uma parte imprescindível da educação dessas mulheres. Diversas são as passagens em que o bispo de Milão irá exortar as viúvas à piedade:

Que grande coisa, portanto, que ofereças tuas moedas e adquiras o corpo de Cristo! Assim, pois, não te apresentes com as mãos vazias na presença do Senhor teu Deus: vazias de misericórdia, vazias de fé, vazias de castidade. Em efeito, o Senhor Jesus não costuma olhar e louvar as que estão vazias, senão as que são ricas em virtudes. [...] Nenhum pagamento é melhor para Deus, que o que está cheio dos dons da piedade (Ambr. De uiduis, 32).

Para Ambrósio (De uiduis, 10), a viúva não deveria estar menos atenta ao dever da piedade religiosa que ao zelo da castidade: "Portanto o mérito da viúva não está apenas na castidade do corpo, senão na práti- 
ca intensa e generosa da virtude: aquela que tem o testemunho das boas obras".

Ao contribuírem com a Igreja doando seu patrimônio, as viúvas tinham o seu o papel público reforçado, apesar da existência de inúmeros códigos que visavam a vetá-lo. Cumprindo com as boas obras, ou seja, praticando a piedade e a caridade para com os pobres, algumas mulheres da aristocracia alcançaram visibilidade e influência, porém foram os bispos os que melhor souberam servir-se da dedicação das mulheres, utilizando-as para fortalecer seu próprio poder. Como destaca Brown (1989, p. 254), "apoiados com firmeza por mulheres celibatárias, os bispos [...] fundamentam seu prestígio sobre a sua capacidade de “alimentar" uma nova categoria anônima e profundamente anticívica dos pobres [...]". Nesse mesmo viés, Zétola (2009) sugere que a institucionalização da caridade exprime uma ideologia fomentada por clérigos para expandir seu poder na sociedade tardo-antiga, uma vez que as próprias desigualdades são perpetuadas e não suprimidas pela piedade. Isto nos leva a crer que a caridade cristã reproduzia relações de poder, tal qual o evergetismo clássico.

Não obstante, podemos destacar que, ao renunciar às práticas sexuais, ao vestir-se de maneira sóbria, ao andar de modo adequado, ao manter o silêncio e abandonar os adornos, regras encontradas ao longo do discurso ambrosiano, as ascetas viúvas se equiparariam às virgens, principalmente no que se refere à superação de uma condição de inferioridade congênita. Como destaca Ambrósio (De uiduis, 1.1): 
Não devemos deixar de honrar, [...] as que a palavra do apóstolo há unido com as virgens, segundo o que está escrito: a mulher casada e a virgem pensam nas coisas que são do Senhor, para serem santas de corpo e espírito. Pois, de certo modo, a doutrina sobre a virgindade se robustece com o exemplo das viúvas.

Pelo testemunho de Ambrósio, podemos inferir que aquilo que se preconiza para as virgens pode ser, no geral, aplicado às viúvas. Ambas, ao observarem a continência, se converterão em exemplos de virtude a ser seguidos, tais como os mártires: “[...] te aproximas dos mártires pelo vínculo da devoção e pelos dons da misericórdia" (De uiduis, 54). E mesmo que as viúvas encontrem-se privadas da virgindade, provam a sua castidade por meio da disciplina, da vigilância e do propósito de permanecerem fiéis a Cristo, não contraindo segundas núpcias. Postas à parte na congregação, deveriam esperar no Senhor, mantendo-se dia e noite em oração, exercendo a hospitalidade, educando bem os filhos e socorrendo os que padecem na tribulação. Contudo, devemos atentar para o fato de que as virgens, as viúvas e as casadas se viabilizam, segundo Ambrósio, dentro de uma hierarquia estabelecida em termos do grau de abstinência da atividade sexual de cada pessoa. Sendo assim, "as virgens vinham em primeiro lugar, as viúvas em segundo, e as pessoas casadas em terceiro" (BROWN, 1990, p.295). Porém, no geral, podemos concluir que todas elas são disciplinarizadas por meio das instituições, leis e costumes vigentes na Igreja.

Em face desse contexto, verificamos que o tratado de Ambrósio representa uma excelente fonte de informação acerca dos princípios que organizaram o movimento ascético no século IV. Aqui, o modelo ideal 
de vida contemplado para a mulher viúva se baseia em um estado permanente de disponibilidade para Deus, por meio da disciplina corporal, como também para a própria comunidade através da caridade. Convertida em um autêntico estado de vida, a viuvez defendida pelos clérigos, permitiu que uma pequena parte das mulheres abastadas do Império desfrutasse de um verdadeiro respeito e reconhecimento públicos. Porém, isso só se tornou viável por meio de um direcionamento espiritual que previa uma rígida doutrinação de seus corpos, capaz até mesmo de modificar os discursos que se fazia acerca da mulher.

\section{Conclusões}

Trabalhar com o mundo feminino durante a Antiguidade Tardia nos possibilitou pensar uma nova maneira de ver e conceber a História partindo de uma perspectiva que aborda a condição da mulher em detrimento de uma historiografia que valoriza os heróis e seus grandes feitos. Seguindo essa vertente, acreditamos que foi possível enriquecer e expandir a História de Gênero por meio dos estudos das relações sociais construídas entre os sexos, principalmente no que se refere, no nosso caso, à relação entre viúvas cristãs da aristocracia citadina e a elite clerical, em meados do século IV. Responsáveis pela construção da representação das virgens e viúvas, os discursos clericais produzidos nesta época permitem analisar o papel social da mulher cristã na Antiguidade e sua ligação com uma vida de virtudes. Tais discursos foram fundamentais na perpetuação da desigualdade de gênero, prevalecendo até os dias atuais. Os escritos clericais não só transmitiram uma série de pres- 
crições de como as mulheres deveriam agir, pensar e falar, como também criaram certezas "absolutas" a respeito da identidade feminina. A própria mulher, quando percebia o corpo feminino através dos discursos masculinos, o fazia de forma natural, justificando toda a divisão existente entre os sexos.

Por conseguinte, a importância da obra de Ambrósio reside no fato de nos permitir compreender as contradições de uma época em que os homens reforçam a ideia de inferioridade feminina, ao passo que algumas mulheres alcançam um protagonismo até então desconhecido na Antiguidade. À margem dos ofícios eclesiásticos, viúvas e virgens ascenderam socialmente, não por uma mudança nos valores cristãos, mas sim porque passaram por um rigoroso processo disciplinar que garantia a formação de um corpo assexuado. Assim, paradoxalmente, ao mesmo tempo em que possuíam, segundo o discurso corrente, uma natureza débil, se comparada ao sexo masculino, a mulher passou a ter a possibilidade de driblar esta suposta "natureza", chegando a desfrutar de um papel de prestígio em uma sociedade de homens. Prestígio este alcançado não apenas pela oração e pela reclusão, mas também pela prática caritativa que as converteram em principais sustentadoras da Igreja.

Mediante nossa investigação, concluímos que dentre outros caminhos que viabilizam a percepção da representação feminina na Antiguidade Tardia, os discursos clericais proporcionam a compreensão do modelo de vida ideal a ser seguido pelas viúvas, principalmente naquilo em que se refere às práticas ascéticas e o zelo pela caridade. Sendo assim, por meio de uma escala de valores que tinha na castidade e na cari- 
dade os princípios basilares da virtude cristã, as viúvas conquistaram seu lugar social, realizando um trabalho contínuo de doutrinação de seus corpos. Ademais, acreditamos que investigar o processo de disciplinarização das viúvas cristãs amplia o campo de pesquisas em torno das questões de gênero, além de oferecer um meio que repense a condição biológica como único fator determinante para as diversas formas de subordinação. Ao invés disso, buscamos investigar como as construções culturais trabalham, definindo e estabelecendo papéis próprios aos homens e às mulheres.

\section{Referências Bibliográficas}

\section{Documentação Primária}

AMBROSIO DE MILAN. Sobre las virgenes y sobre las viudas. Madrid: Ciudad Nova, 1999.

Bíblia sagrada. Tradução: João Ferreira de Almeida. 2a . ed rev. São Paulo: Sociedade Bíblica do Brasil, 1982. Cap. 7, vers. 39-40.

\section{Referências complementares}

ALEXANDRE, M. Do anúncio do Reino à Igreja: Papéis, ministérios, poderes femininos. In: DUBY, G. \& PERROT, M. (Org) História das Mulheres: A Antinguidade. Porto: 1990. p. 513- 559.

BOURDIEU, Pierre. A dominação masculina. Rio de Janeiro: Bertrand Brasil, 2002.

BUTLER, J. Corpos que pesam: sobre os limites discursivos do 'sexo'. In: LOURO, G. L. (Org.). O corpo educado: pedagogias da sexualidade. Belo Horizonte: Autêntica, 2000. p. 151-172. 
BROWN, P. Corpo e sociedade: o homem, a mulher e a renúncia sexual no início do cristianismo. RJ: Jorge Zahar, 1990.

BROWN, P. Antiguidade Tardia. In ARIES, P. \& DUBY, G. (org.) História da vida privada. vol. 1 São Paulo: Companhia das Letras, 1989.

CHARTIER, R. A história cultural: entre práticas e representações. Lisboa: Difel, 1990.

GUARINEllo, L. N. História Antiga. São Paulo: Contexto. 2013. p. 162-174.

LEMOS, M. S. As relações de poder entre o estado romano e a igreja: uma história de conflito e conciliação, Revista brasileira de história das religiões, n. 17, p. 29-51, 2013.

LEMOS, M. S. Os embates entre cristãos e pagãos no império romano do século IV: discurso e recepção, Dimensões, vol. 28, p. 153-172, 2012.

OLIVEIRA, W. F; A Antiguidade Tardia. São Paulo: Ática, 1990.

SCHEID, J. Estrangeiras indispensáveis: os papéis religiosos das mulheres em Roma. In: DUBY, G. \& PERROT, M. (Org) História das Mulheres: A Antinguidade. Porto: 1990. p. 513- 559.

SÁEZ, Rosario N. La mujer al final de la antigüedad: las viudas profesas. In: Luna, L. G. (Comp.) Mujeres e sociedad. Barcelona: Universitat de Barcelona, 1991.

SCOTT, Joan Wallach. Gênero: uma categoria útil de análise histórica. Educação \& Realidade, Porto Alegre, vol. 20, nº 2, jul./dez., p. 71-99, 1995.

SERRATO, Mercedes. La experiência ascética de las viudas de la aristocracia senatorial romana: mas allá de la oración, Saitabi, n.49, p.341359, 1999. 
SILVA, G. V. da. A apropriação do território urbano pelos cristãos no fim do império romano. In: CAMPOS, A. P.; SILVA, G. V. da.; NADER M. B.; FRANCO, S. P.; FELDMAN S. A. (Orgs.) A cidade à prova do tempo: vida cotidiana e relações de poder nos ambientes urbanos. Vitória: GM, 2010. p. 63- 79.

SILVA, G. V. da. A redefinição do papel feminino na Igreja Primitiva: virgens, viúvas, diaconisas e monjas. In: SILVA, G. V. da., NADER, M. B., FRANCO, S. P. (Orgs.) As identidades no tempo: ensaios de gênero, etnia e religião. Vitória: EDUFES, 2006, p. 305 - 320.

SILVA, G. V. da. Ascetismo, Gênero e Poder no Baixo Império Romano:Paládio de Helenópolis e o status das Devotas Cristãs, História, n. 26, p. 63-78, 2007.

SILVA, G. V; SOARES, C. S. Autoridade episcopal e conflito político na Antiguidade Tardia: a atuação de Cipriano de Cartago e de João Crisóstomo como reformadores da Igreja, Revista brasileira de História das Religiões, Ano IV, n. XIII, p. 141-160.

SIQUEIRA, S. M. A. A efervescência discursiva sobre as mulheres nos movimentos marginais do cristianismo primitivo e as respostas patrísticas. In: FEITOSA, L. C.; FUNARI, P. P. A.; SILVA, G. J. da. (Org.) Amor, desejo e poder na antigüidade: relações de gênero e representações do feminino. SP: UNICAMP, 2003, p. 375-390.

SIQUEIRA, S. M. A. Reflexões sobre política e igreja no século IV: um olhar para as mulheres cristãs, Dimensões, n. 25, p. 148-163, 2010.

TEDESCHI. L. A. História das mulheres e as representações do feminino. São Paulo: Curt Nimuendajú, 2008

TEJA, R. Emperadores, obispos, monjes y mujeres. Madrid: Editorial Trotta, 1999.

ULlMANN, W. Historia Del pensamiento político en Edad Media. Barcelona: Ariel, 1983. 
Cadernos de Clio, Curitiba, v. 6, nº. 2, 2015

ZÉTOLA, Bruno M. Da Antiguidade ao Medievo: o cristianismo e a elaboração de um novo modelo caritativo, Saeculum, n.11, p. 54-71, 2004.

ZÉTOLA, Bruno M. Pobreza, caridade e poder na Antiguidade Tardia. Curitiba: Juruá, 2009.

Recebido em: 04/06/2015 Aceito em: 16/10/2015 